\title{
Article \\ Electroless Ni-P Plating on Mullite Powders and Study of the Mechanical Properties of Its Plasma-Sprayed Coating
}

\author{
Kaiwang Chen ${ }^{1,2}$, Penglin Zhang ${ }^{1,2, *}$, Pengfei Sun ${ }^{1,2}$, Xianming Niu ${ }^{2}$ and Chunlian $\mathrm{Hu}^{2}$ \\ 1 State Key Laboratory of Advanced Processing and Recycling of Nonferrous Metals, Lanzhou University of \\ Technology, Lanzhou 730050, China; ckwvip@163.com (K.C.); 15836996274@163.com (P.S.) \\ 2 School of Materials Science and Engineering, Lanzhou University of Technology, Lanzhou 730050, China; \\ niuxm@lut.cn (X.N.); hucl@lut.edu.cn (C.H.) \\ * Correspondence: zhangpl@lut.edu.cn
}

Citation: Chen, K.; Zhang, P.; Sun, P.; Niu, X.; Hu, C. Electroless Ni-P Plating on Mullite Powders and Study of the Mechanical Properties of Its Plasma-Sprayed Coating. Coatings 2022, 12, 18. https://doi.org/ 10.3390/coatings12010018

Academic Editor: Silvia

Maria Deambrosis

Received: 24 November 2021

Accepted: 18 December 2021

Published: 24 December 2021

Publisher's Note: MDPI stays neutral with regard to jurisdictional claims in published maps and institutional affiliations.

Copyright: (C) 2021 by the authors. Licensee MDPI, Basel, Switzerland. This article is an open access article distributed under the terms and conditions of the Creative Commons Attribution (CC BY) license (https:// creativecommons.org/licenses/by/ $4.0 /)$.

\begin{abstract}
To effectively improve the properties of a mullite coating and its interfacial bonding with the substrate, a Ni-P layer is deposited on the surface of mullite powders by electroless plating. The original mullite powders and coated mullite powders are then deposited onto stainless-steel substrates by plasma spraying. The growth mechanism of the Ni-P layer during the plating, the microstructures of the coated powders and mullite coating and the properties of the mullite coatings are characterized and analyzed. The results indicate that the Ni-P layer on the surface of the mullite powder has cell structures with a dense uniform distribution and grows in layers on the surface of the mullite powder. The crystallization behavior of Ni-P amorphous layer is induced by heat treatment. Compared to the original mullite coating, the coating prepared by the coated mullite powders has better manufacturability, stronger adhesion to the substrate, lower porosity $(7.40 \%, 65 \%$ of that of the original coating), higher hardness ( $500.1 \mathrm{HV}, 1.2$ times that of the original coating), and better thermal cycle resistance (two times that of the original coating). The method of preparation of high-temperature thermal barrier coatings with coated mullite powders has a high application value.
\end{abstract}

Keywords: electroless plating; plasma spraying; mullite; thermal cycle resistance

\section{Introduction}

High-temperature components used in modern aerospace applications, aircraft manufacturing, and internal combustion engines usually bear high thermomechanical loads. To improve the properties and service lives of high-temperature components, thermal barrier coatings (TBCs) are often fabricated on the surface of the metallic substrate [1-4]. Generally, the methods for the preparation of TBCs include laser cladding, electron beam physical vapor deposition, and plasma spraying [5-8]. Among them, plasma spraying has a high commercial application value owing to its high deposition rate, low economic cost, and high coating speed.

Among the various thermal barrier materials, mullite is often used as a material for TBCs of diesel engines owing to its low thermal conductivity, high-temperature resistance, creep resistance, and chemical stability $[9,10]$. However, there is a large coefficient of thermal expansion (CTE) mismatch between mullite and metallic substrates. Thus, the thermal stress accumulation between the mullite coating and metallic substrate at high temperatures (around $1000{ }^{\circ} \mathrm{C}$ ) can peel off the coating. In addition, cracks occur during recrystallization of mullite at high temperatures, which hinders the application of mullite in TBC [11]. In recent years, some researchers used the method of designing gradient coating and introducing a secondary phase to solve the above problems [12-15]. Zhang et al. [16] prepared a functionally graded environmental barrier coating containing mullite on $\mathrm{a} \mathrm{SiC}_{\mathrm{f}} / \mathrm{SiC}$ composite by plasma spraying-physical vapor deposition and studied the thermomechanical properties of the coating. Vakilifard et al. [17] prepared two-layer functionally graded $\mathrm{ZrO}_{2} / \mathrm{NiCrAlY}$ coatings on an Inconel 738LC alloy substrate 
by atmospheric plasma spraying (APS) and evaluated their corrosion behaviors in a molten salt corrosion environment. Li et al. [11] used APS to prepare a functional gradient mullite coating on an Inconel 718 alloy substrate and introduced $\mathrm{ZrO}_{2}$ secondary phase to study its thermomechanical properties and thermal cycle resistance. However, owing to the intrinsic brittleness of mullite and its low interface bonding with the metallic substrate, the coating tends to crack and peel off in a thermal shock environment. Electroless plating is expected to be an effective method to enhance the interfacial bonding between mullite and metallic substrate owing to its good uniform plating ability and high bonding ability between the coated powders and metallic substrates [18-21]. However, only a few studies on electroless plating of mullite powders have been carried out.

In this study, a Ni-P layer was coated on the surface of the mullite powder by electroless plating to improve the toughness and CTE of the mullite powder. Then the original mullite powders and coated mullite powders were used to fabricate coatings on a pretreated 304 stainless-steel substrate by plasma spraying. Subsequently, the growth mechanism of the Ni-P layer on the mullite powder surface was studied. The microstructures, phase constituents, hardnesses, porosities, thermal cycle behaviors, and thermal barrier properties of the two coatings were compared and analyzed.

\section{Experimental Methods}

\subsection{Materials}

Mullite $\left(3 \mathrm{Al}_{2} \mathrm{O}_{3} \cdot 2 \mathrm{SiO}_{2}\right.$; Zhengdeng refratory Co., Ltd., Zhengzhou, China) powders with average particle sizes of 30-60 $\mu \mathrm{m}$ were used as raw powders for the deposition of the $\mathrm{Ni}-\mathrm{P}$ layer. In the electroless plating, sodium hydroxide $(\mathrm{NaOH})$, hydrochloric acid $(\mathrm{HCl})$, hydrofluoric acid ( $\mathrm{HF})$, stannous chloride $\left(\mathrm{SnCl}_{2}\right)$, nickel sulfate hexahydrate $\left(\mathrm{NiSO}_{4} \cdot 6 \mathrm{H}_{2} \mathrm{O}\right)$, sodium hypophosphite $\left(\mathrm{NaH}_{2} \mathrm{PO}_{2} \cdot \mathrm{H}_{2} \mathrm{O}\right)$, sodium citrate $\left(\mathrm{Na}_{3} \mathrm{C}_{6} \mathrm{H}_{5} \mathrm{O}_{7} \cdot 2 \mathrm{H}_{2} \mathrm{O}\right)$, and ammonium chloride $\left(\mathrm{NH}_{4} \mathrm{Cl}\right)$ analytical reagents (Tianjin Baishi Chemical Co., Ltd., Tianjin, China) were used. Palladium chloride $\left(\mathrm{PdCl}_{2}\right)$ used for activation was purchased from Shenyang Institute of Nonferrous Metals (Shenyang, China). The original mullite and coated mullite were deposited on 304 stainless-steel substrates $(\Phi 24 \mathrm{~mm} \times 8 \mathrm{~mm})$ with an APS-9M system (Sulzer-Metco, Winterthur, Switzerland). The chemical composition of the 304 stainless steel is shown in Table 1.

Table 1. Chemical composition of the 304 stainless steel.

\begin{tabular}{cccccccccc}
\hline Element & $\mathbf{C}$ & $\mathbf{S i}$ & $\mathbf{M n}$ & $\mathbf{P}$ & $\mathbf{S}$ & $\mathbf{N i}$ & $\mathbf{C r}$ & $\mathbf{N}$ & $\mathbf{F e}$ \\
\hline $\mathrm{wt} . \%$ & 0.07 & 0.37 & 1.27 & 0.03 & 0.01 & 8.02 & 17.2 & 0.06 & Balance \\
\hline
\end{tabular}

\subsection{Preparation of the Ni-P-Coated Mullite Powders}

\subsubsection{Pretreatment of the Mullite Powders}

The surface modification is illustrated in Figure 1. Mullite powders were pretreated before electroless plating. The steps included coarsening, sensitization, and activation. The mullite powders were dipped into a $25 \mathrm{wt} . \% \mathrm{HF}$ solution for $10 \mathrm{~min}$ to obtain a coarse surface. The coarsened mullite powders were immersed into a solution of $16 \mathrm{~g} / \mathrm{L} \mathrm{SnCl}_{2}$ and $40 \mathrm{~mL} / \mathrm{L} \mathrm{HCl}$ at $40{ }^{\circ} \mathrm{C}$ for $20 \mathrm{~min}$. Finally, the mullite powders were poured into an activator solution containing $0.3 \mathrm{~g} / \mathrm{L} \mathrm{PdCl}_{2}$ and $4 \mathrm{~mL} / \mathrm{L} \mathrm{HCl}$ at $40{ }^{\circ} \mathrm{C}$ for $40 \mathrm{~min}$, which improved the subsequent interaction between the surface and electroless plating solution. After coarsening, the mullite powders were rinsed with a large volume of deionized water to neutralize the $\mathrm{pH}$ and dried after activation. During the activation process, $\mathrm{Pd}^{2+}$ ions were reduced to Pd atoms by $\mathrm{Sn}^{2+}$, which was ready for the next electroless Ni-P plating. 


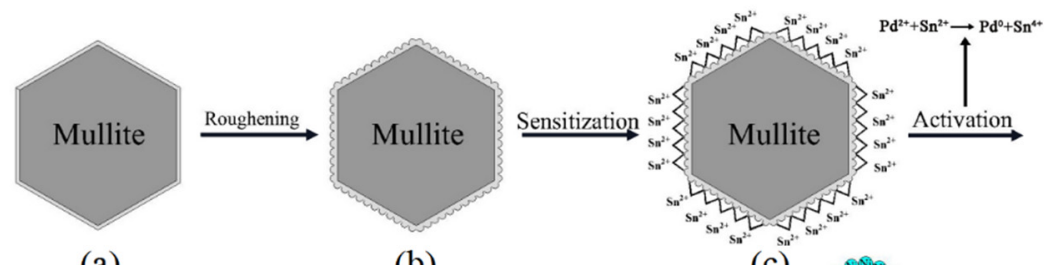

(a)

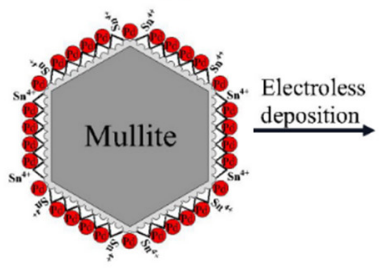

(d) (b)

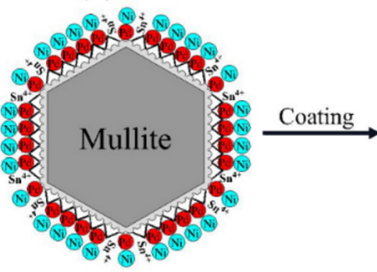

(e)

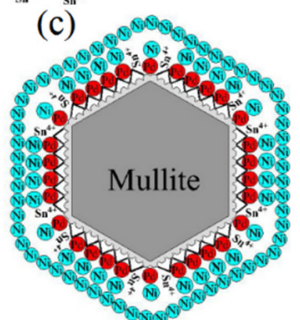

(f)

Figure 1. Electroless Ni-P plating.

\subsubsection{Orthogonal Experimental Design of Electroless Plating}

The parameters of the plating solution were optimized by an orthogonal test. Four factors were considered in this experiment: $\left[\mathrm{NiSO}_{4} \cdot 6 \mathrm{H}_{2} \mathrm{O}\right](\mathrm{A}),\left[\mathrm{NaH}_{2} \mathrm{PO}_{2} \cdot \mathrm{H}_{2} \mathrm{O}\right](\mathrm{B})$, temperature $(\mathrm{C})$, and $\mathrm{pH}(\mathrm{D})$. Through measuring the relative weight gain of $1 \mathrm{~g}$ powders after electroless plating, the optimal process parameters of the Ni-P plating on the mullite powder surface were obtained: $\left[\mathrm{NiSO}_{4} \cdot 6 \mathrm{H}_{2} \mathrm{O}\right]=20 \mathrm{~g} / \mathrm{L},\left[\mathrm{NaH}_{2} \mathrm{PO}_{2} \cdot \mathrm{H}_{2} \mathrm{O}\right]=30 \mathrm{~g} / \mathrm{L}$, temperature $=80^{\circ} \mathrm{C}$, and $\mathrm{pH}=5.5$. Table 2 shows the design factors along with their levels.

Table 2. Design factors and their levels.

\begin{tabular}{ccccc}
\hline Level & $\begin{array}{c}\text { Nickel Sulfate } \\
\text { Hexahydrate (A)/(g/L) }\end{array}$ & $\begin{array}{c}\text { Factor } \\
\text { Sodium } \\
\text { Hypophosphite } \\
(\mathbf{B}) /(\mathrm{g} / \mathrm{L})\end{array}$ & $\begin{array}{c}\text { Temperature } \\
\text { (C)/ }{ }^{\circ} \mathbf{C}\end{array}$ & $\mathrm{pH}(\mathbf{D})$ \\
\hline 1 & 15 & 10 & 40 & 4.5 \\
2 & 20 & 20 & 60 & 5 \\
3 & 25 & 30 & 80 & 5.5 \\
\hline
\end{tabular}

\subsubsection{Electroless Plating with Ni-P}

The electroless Ni-P plating was carried out on the pretreated mullite powders with the optimal bath parameters. The electroless plating was conducted at $80^{\circ} \mathrm{C}$ for $1 \mathrm{~h}$. The powders were suspended by magnetic stirrers during the reaction to achieve a good plating effect. After the reaction, the coated powders were separated from the solution by filtration and washed three times with deionized water. Finally, the Ni-P/mullite composite powders were obtained after drying at $100{ }^{\circ} \mathrm{C}$ for $3 \mathrm{~h}$.

In the process of electroless Ni-P plating, the initiation of Ni-P deposition is controlled by an anodic process. The first step involves a non-Faradaic step, namely the adsorption of hypophosphite on the surface of the catalyst [22]. Then the homolytic breakdown of $\mathrm{Ni}-\mathrm{P}$ bond occurs. The hydrogen in the reaction comes from the reducing agent sodium hypophosphite. The homolytic breakdown of Ni-P bond not only accelerates the deposition rate of the secondary phosphate ion dehydrogenation but also improves the activity of $\mathrm{H}_{2} \mathrm{PO}_{2}{ }^{-}$[19]. In the process of plating, the Ni-P layer is first deposited near the catalyst. The chemical reactions during electroless plating are depicted as follows:

$$
\begin{gathered}
\mathrm{H}_{2} \mathrm{PO}_{2}{ }^{-} \rightarrow \mathrm{HPO}_{2}{ }^{-}+\mathrm{H} \\
\mathrm{HPO}_{2}{ }^{-}+\mathrm{H}_{2} \mathrm{O} \rightarrow \mathrm{H}_{2} \mathrm{PO}_{3}{ }^{-}+\mathrm{H}^{+}+\mathrm{e} \\
\mathrm{H}+\mathrm{H} \rightarrow \mathrm{H}_{2}
\end{gathered}
$$




$$
\begin{gathered}
2 \mathrm{H}^{+}+2 \mathrm{e} \rightarrow \mathrm{H}_{2} \\
\mathrm{Ni}^{2+}+2 \mathrm{e} \rightarrow \mathrm{Ni} \\
\mathrm{H}_{2} \mathrm{PO}_{2}{ }^{-}+2 \mathrm{H}^{+}+2 \mathrm{e} \rightarrow \mathrm{P}+2 \mathrm{H}_{2} \mathrm{O}
\end{gathered}
$$

\subsection{Preparation of Coatings}

Before the plasma spray deposition, the stainless-steel substrate was sand-blasted with $300 \mu \mathrm{m} \mathrm{SiC}$ particles and cleaned with an acetone solution in an ultrasonic bath for $15 \mathrm{~min}$ to roughen the surface and ensure good adhesion between the coating and substrate. A NiCrAlY bond coating (approximately $100 \mu \mathrm{m}$ ) was sprayed on the substrate before the preparation of the mullite coating to reduce the residual thermal stress between the substrate and coating. The coatings fabricated by original mullite powders and coated mullite powders are denoted as $\mathrm{O}_{C}$ and $\mathrm{N}_{C}$, respectively. The APS parameters selected in this study are shown in Table 3.

Table 3. APS parameters.

\begin{tabular}{ccc}
\hline Parameters & NiCrAlY Coating & Mullite Coating \\
\hline Arc current $(\mathrm{A})$ & 600 & 500 \\
Voltage $(\mathrm{V})$ & 60 & 70 \\
Argon gas flow rate $(\mathrm{L} / \mathrm{min})$ & 40 & 45 \\
Hydrogen gas flow rate $(\mathrm{L} / \mathrm{min})$ & 15 & 15 \\
Powder gas flow rate $(\mathrm{L} / \mathrm{min})$ & 5 & 8 \\
Spray distance $(\mathrm{mm})$ & 90 & 90 \\
Spray angle $\left({ }^{\circ}\right)$ & 90 & 90 \\
Gun speed $(\mathrm{m} / \mathrm{s})$ & 0.3 & 0.2 \\
\hline
\end{tabular}

\subsection{Thermal Cycle Test of the Coatings}

The thermal cycle tests were carried out in a muffle furnace (SX-G07123, Tianjin zhonghuan electric furnace Co., Ltd., Tianjin, China, $10{ }^{\circ} \mathrm{C} / \mathrm{min}$ ). After processing in a muffle furnace at $800{ }^{\circ} \mathrm{C}$ for $15 \mathrm{~min}$, the sprayed samples were quickly removed from the furnace and cooled in water at $10^{\circ} \mathrm{C}$. When the samples were completely cooled, they were removed and dried with compressed air. At each interval of cooling, the furnace was maintained at $800{ }^{\circ} \mathrm{C}$. The cooled samples were placed in the furnace again to conduct the second cycle of thermal tests. The process was repeated until an area equivalent to $5 \%$ of the coatings was debonded from the substrate. All the processes above were shown in Figure 2 .

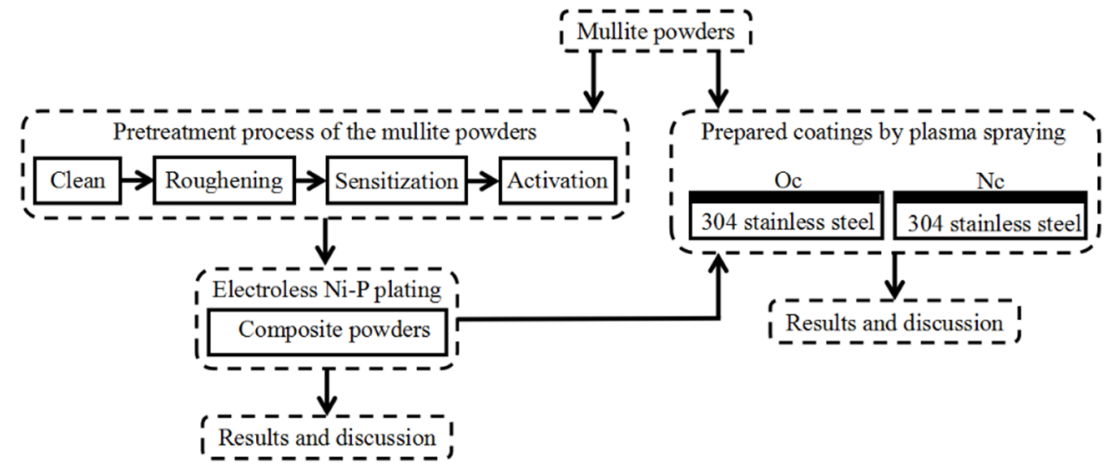

Figure 2. The flow chart of the experimental process.

\subsection{Characterization of the Coated Mullite Powders and As-Sprayed Coatings}

Before the microscopic characterization, the coated powders were embedded in carbon powders, and then mechanically polished to obtain the cross section of the coated powders. The morphologies of the coated mullite powders and as-sprayed coatings were analyzed by scanning electron microscopy (SEM, JSM-6700F, JEOL, Tokyo, Japan) equipped with 
energy-dispersive spectrometry (EDS). X-ray photoelectron spectroscopy (XPS; PHI-5702, $\mathrm{Al} \mathrm{K}_{\alpha}$ radiation, Thermo Fisher Scientific, Massachusetts, America) was used to analyze the surface compositions and chemical states of the coated powders. To obtain the cross section morphologies of the coated powder and sprayed coating, the cross sections of the coated powder and coating were mechanically polished. The phase compositions of the coated mullite and the coatings were determined using X-ray diffraction (XRD; D8 ADVANCE, $\mathrm{Cu}-\mathrm{K}_{\alpha}$ radiation, Brukeroptics, Karlsruhe, Germany).

The microhardnesses of the polished surfaces of the as-prepared coatings were measured by an HDX-1000 digital hardness tester (Shangcai Testermachine Co., Ltd., shanghai, China) with a load of $200 \mathrm{~g}$ and dwell time of $10 \mathrm{~s}$. The microhardnesses of the coatings were the average values of 15 indentation points. The porosities of the as-sprayed coatings were calculated by the software version Image J (National Institutes of Health, Bethesda, America). The densities $(\rho)$ of the coatings were measured by water immersion. A DRE-III thermal conductivity instrument was used to determine the thermal diffusivity $(\alpha)$ and thermal conductivity $(K)$ of the as-sprayed coating by the transient plane source (TPS) method. The specific heat capacity $\left(C_{p}\right)$ of the coating was calculated as: $K=\alpha \rho C_{p}$.

\section{Results and Discussion}

\subsection{Microstructures and Phase Compositions of the Ni-P/Mullite Composite Powders}

Figure 3 shows SEM images of the coated powders with different $\mathrm{NaH}_{2} \mathrm{PO}_{2} \cdot \mathrm{H}_{2} \mathrm{O}$ concentrations when the others factors are constant. Figure $3 \mathrm{~d}$ shows that the Ni-P layer is coated on the surface of the mullite powder. To better elucidate the nucleation and growth of the Ni-P layer in electroless plating, mullite powders were coated when the concentrations of $\mathrm{NaH}_{2} \mathrm{PO}_{2} \cdot \mathrm{H}_{2} \mathrm{O}$ were 10,20 , and $30 \mathrm{~g} / \mathrm{L}$. Figure 3 a shows that, under the catalysis of discontinuous $\mathrm{Pd}$ sites, Ni particles start to nucleate at the activation centers and grow in situ, which leads to an island-like structure and leakage plating phenomenon. Figure $3 \mathrm{~b}$ illustrates that a uniform Ni-P layer was coated on the surface of mullite. Ni-P particles formed a secondary structure on the surface of mullite, because the deposited Ni-P film acted as an activation center, where a new island-shaped Ni nucleus was formed at the position of a Pd site. Notably, no obvious leakage of plating was observed. Figure 3c,d show that the Ni-P layer is uniformly distributed on the surface of the mullite powder without aggregation layer. A good Ni-P layer was formed on the surface of the mullite powder by orthogonal test.

Figure 4 shows the EDS analysis of the Ni-P/mullite composite powder under the optimized conditions. Figure 4c shows EDS results of area A in Figure 4a. It reveals that the $\mathrm{Ni}$ and $\mathrm{P}$ contents in the deposits are 83.22 and $5.82 \mathrm{wt} . \%$, respectively. Figure $4 \mathrm{~d}$ shows scanning results along line $\mathrm{B}$ in Figure $4 \mathrm{~b}$. Ni and $\mathrm{P}$ are distributed mainly on the surface of the composite powder, while $\mathrm{Al}, \mathrm{Si}$, and $\mathrm{O}$ are distributed in the core part of the composite powder. The average thickness of the Ni-P layer is approximately $2 \mu \mathrm{m}$ when the plating is completed. These results combined with the SEM images show that a Ni-P layer is well formed on the surface of the mullite powder, which is conducive to bonding with the substrate.

The XRD patterns of the mullite powders, $\mathrm{Ni}-\mathrm{P} /$ mullite coated powders, and coated powders after the heat treatment $\left(850^{\circ} \mathrm{C}\right.$ for $60 \mathrm{~min}$ ) are shown in Figure 5. As shown in Figure $5 \mathrm{~b}$, the coated powders exhibited a broad band at $2 \theta=45^{\circ}$, which is a typical feature of the amorphous structure. During the plating process, the metalloid $\mathrm{P}$ was reduced into the Ni-P layer with $\mathrm{Ni}$, which hindered the arrangement of $\mathrm{Ni}$ atoms into the face-centered cubic structure. Therefore, the layer microstructure gradually changed from microcrystalline to amorphous with a disordered arrangement [23]. Under the protection of argon, the coated powders were heat-treated at $850{ }^{\circ} \mathrm{C}$ for $60 \mathrm{~min}$. As shown in Figure $5 \mathrm{c}$, after the heat treatment, the broad band of the coated powders at $2 \theta=45^{\circ}$ disappeared; sharp crystal peaks of the equilibrium phases of $\mathrm{Ni}$ and $\mathrm{Ni}_{3} \mathrm{P}$ were formed. The layer changed from amorphous to crystalline. During the heat treatment, the Ni-P layer initially exhibited structural relaxation with the increase in temperature, and then diffusion migration of $\mathrm{P}$ 
occurred, which yielded the formation of $\mathrm{Ni}$ crystals and metastable intermediate phases, such as $\mathrm{Ni}_{8} \mathrm{P}_{3}$ and $\mathrm{Ni}_{12} \mathrm{P}_{5}[18,24]$. As the temperature further increased, the metastable intermediate phases decomposed to $\mathrm{Ni}_{3} \mathrm{P}$ and, finally, the alloy transformed from amorphous to crystalline. During the heat treatment, the dispersed distribution of $\mathrm{Ni}_{3} \mathrm{P}$ precipitated by the recrystallization changed the arrangement of $\mathrm{Ni}$ and $\mathrm{P}$ atoms, which effectively prevented the movement of grain boundaries and dislocations [25].
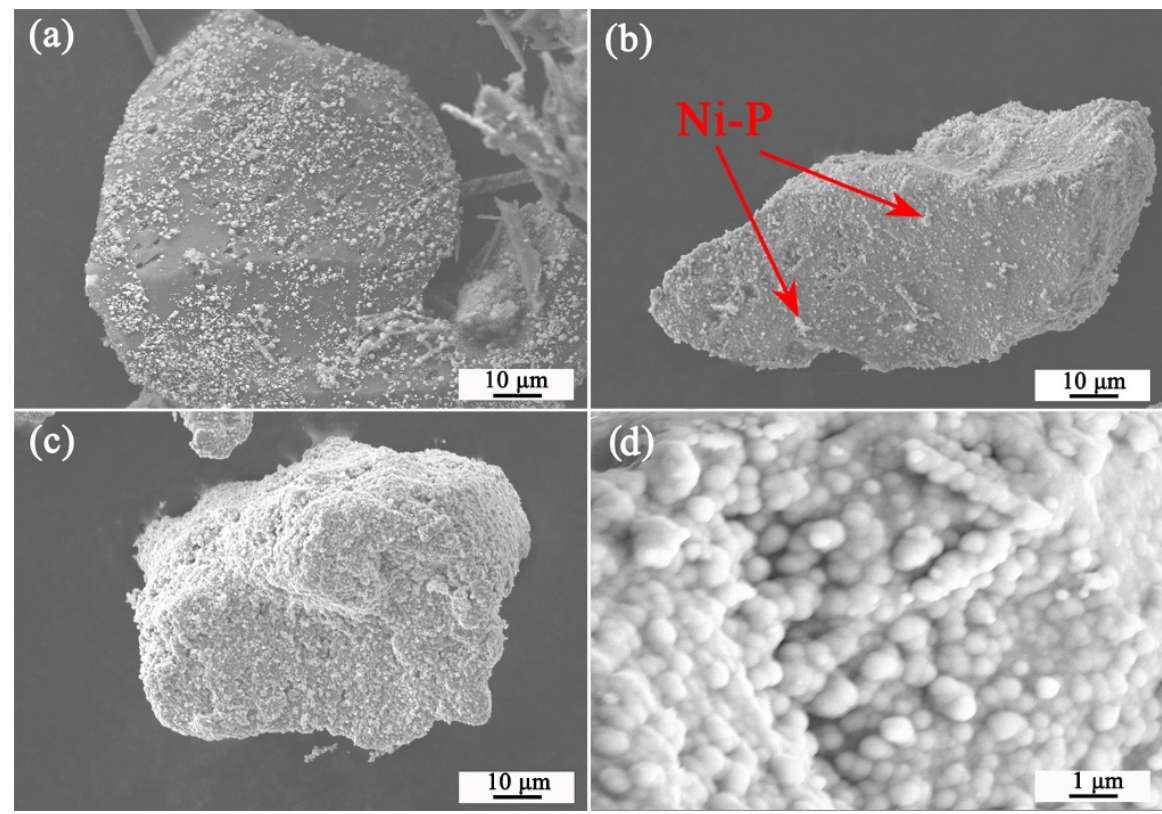

Figure 3. SEM images of the Ni-P layers with $\mathrm{NaH}_{2} \mathrm{PO}_{2} \cdot \mathrm{H}_{2} \mathrm{O}$ concentrations of (a) 10, (b) 20, and (c) $30 \mathrm{~g} / \mathrm{L}$. (d) Magnified image of (c).
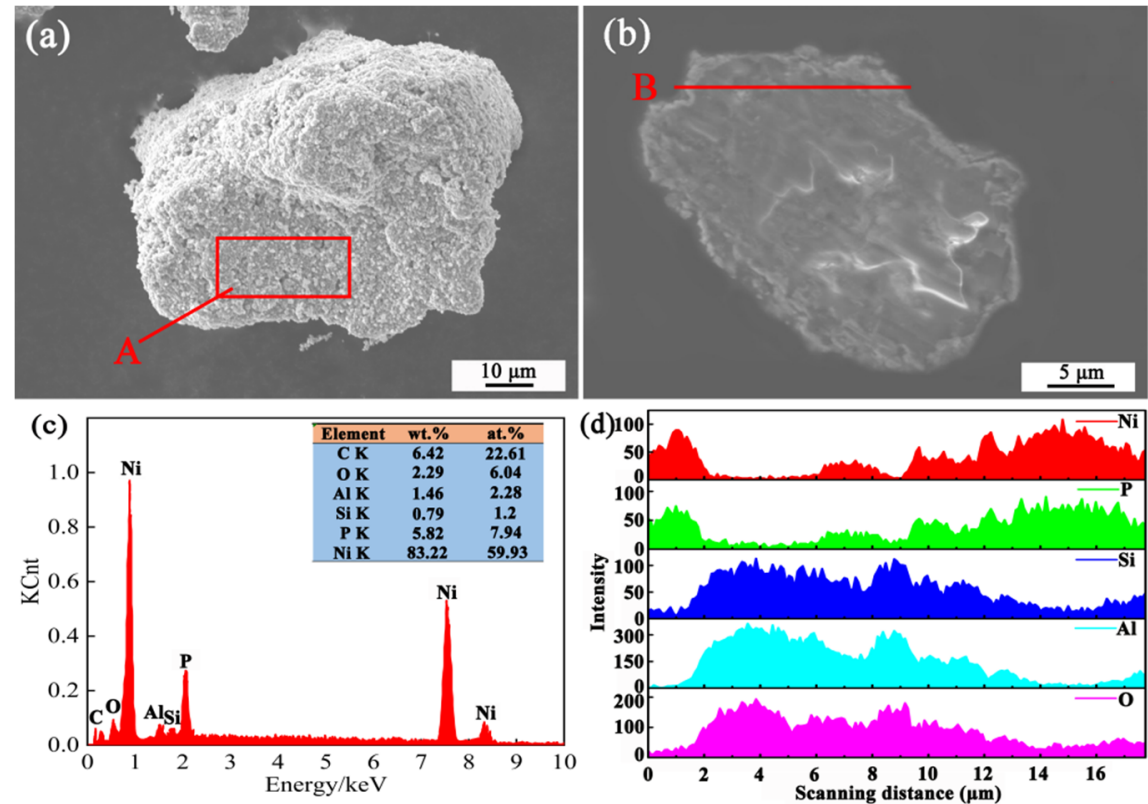

Figure 4. EDS analysis of the Ni-P/mullite composite powder: (a) surface, (b) cross section, (c) EDS of area $\mathrm{A}$, and (d) scans along line B. 


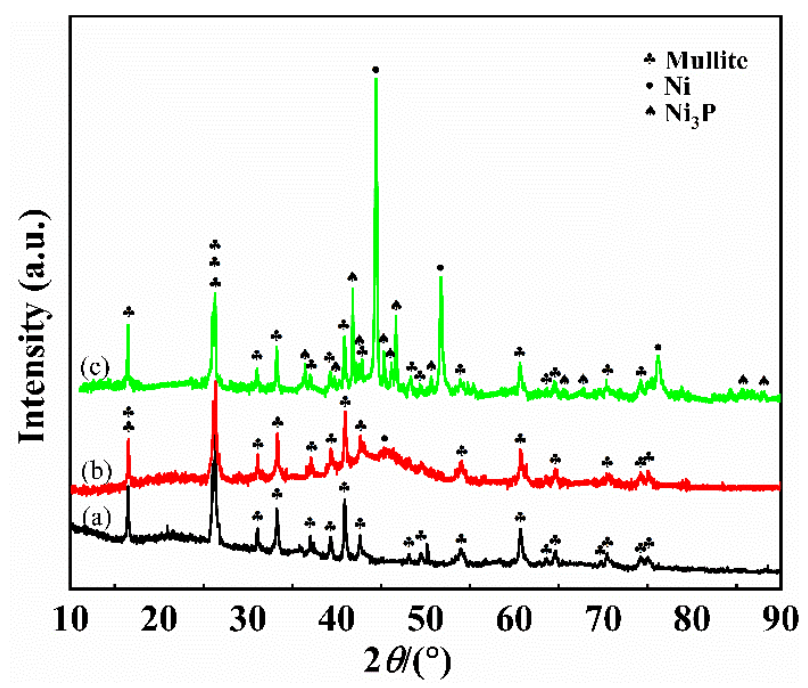

Figure 5. XRD patterns of the powders before and after the electroless plating: (a) raw mullite powders, (b) Ni-P/mullite composite powders, and (c) heat treatment at $850{ }^{\circ} \mathrm{C}$ for $60 \mathrm{~min}$.

The surface analysis of the Ni-P/mullite composite powder was carried out using XPS (Figure 6). Figure 6a shows $\mathrm{C}, \mathrm{O}, \mathrm{Al}, \mathrm{Si}, \mathrm{Ni}$, and $\mathrm{P}$ elements on the surface of the mullite powder. $C$ in the spectrum originated mainly from surface contamination [26]. $\mathrm{Ni}$ is one of the elements with the highest contents, while the content of $\mathrm{P}$ is relatively low. This indicates that the Ni-P layer was coated on the surface of the mullite powders during the electroless plating. To characterize the surface chemical state of the coated powder, high-resolution XPS spectra of Ni 2p, P 2p, and O 1s were acquired. The spectrum of Ni 2 $p_{3 / 2}$ (Figure 6b) is decomposed into three peaks. According to the reference [24], the peak at $856.1 \pm 0.1 \mathrm{eV}$ is attributed to $\mathrm{Ni}^{2+}$ in $\mathrm{Ni}_{3}(\mathrm{PO} 4)_{2}$. The peaks at $861.5 \pm 0.1$ and $852.8 \pm 0.1 \mathrm{eV}$ are attributed to $\mathrm{Ni}^{2+}$ in $\mathrm{Ni}(\mathrm{OH})_{2}$ and $\mathrm{Ni}$ in the layer, respectively. In Figure $6 \mathrm{c}$, the high-resolution curves of $\mathrm{P} 2 \mathrm{p}_{3 / 2}$ are composed mainly of two peaks at $129.6 \pm 0.1$ and $133.0 \pm 0.1 \mathrm{eV}$. The peak at $129.6 \pm 0.1 \mathrm{eV}$ originates from $\mathrm{P}$ in the layer, while the peak at $133.0 \pm 0.1 \mathrm{eV}$ is attributed to $\mathrm{P}^{5+}$ in $\mathrm{Ni}_{3}(\mathrm{PO} 4)_{2}$. Figure $6 \mathrm{~d}$ shows the high-resolution spectrum of $\mathrm{O} 1 \mathrm{~s}$, which corresponds to mainly $\mathrm{O}^{2-}$ in a series of oxygencontaining compounds. The XPS spectrum shows that the surface of the coated powder layer is composed mainly of $\mathrm{Ni}_{3}(\mathrm{PO} 4)_{2}, \mathrm{Ni}(\mathrm{OH})_{2}, \mathrm{Ni}$, and $\mathrm{P}$.

\subsection{Microstructure and Phase Compositions of the Coatings}

Figure 7 shows top views of the as-sprayed coatings and their polished cross sections. As shown in Figure 7a,b, the as-sprayed coatings are relatively rough and contain numerous flattened particles, some semimolten particles, and few pores. Compared to $\mathrm{O}_{\mathrm{C}}$ (Figure 7a), the coated mullite powders in $N_{C}$ (Figure $7 b$ ) were partially melted, while some mullite powders were uniformly embedded in the area of the flattened zone and semimolten powders. This may be attributed to the presence of the Ni-P layer on the surface of the coated powders. At the same power, the particles injected in the center of the plasma jet can be completely melted and can form molten droplets that are accelerated to hit the substrate with a high kinetic energy. While the particles were injected at the periphery of the plasma jet, a part of the spraying heat was absorbed by the Ni-P layer. As a result, a part of the coated mullite powder was directly embedded on the surface of the substrate without melting [27]. There were no obvious cracks between the mullite coating and metallic layer. Figure 7c,d shows back-scattered electron (BSE) images of Oc and Nc, respectively. Compared to $\mathrm{O}_{\mathrm{C}}$, there are numerous white spots of the Ni-P layer uniformly distributed in the cross section of $\mathrm{N}_{\mathrm{C}}$. There are also a few pores in the coating, which mainly originate from the escape of gas inside the coating and boundary closure of the melting zone. 

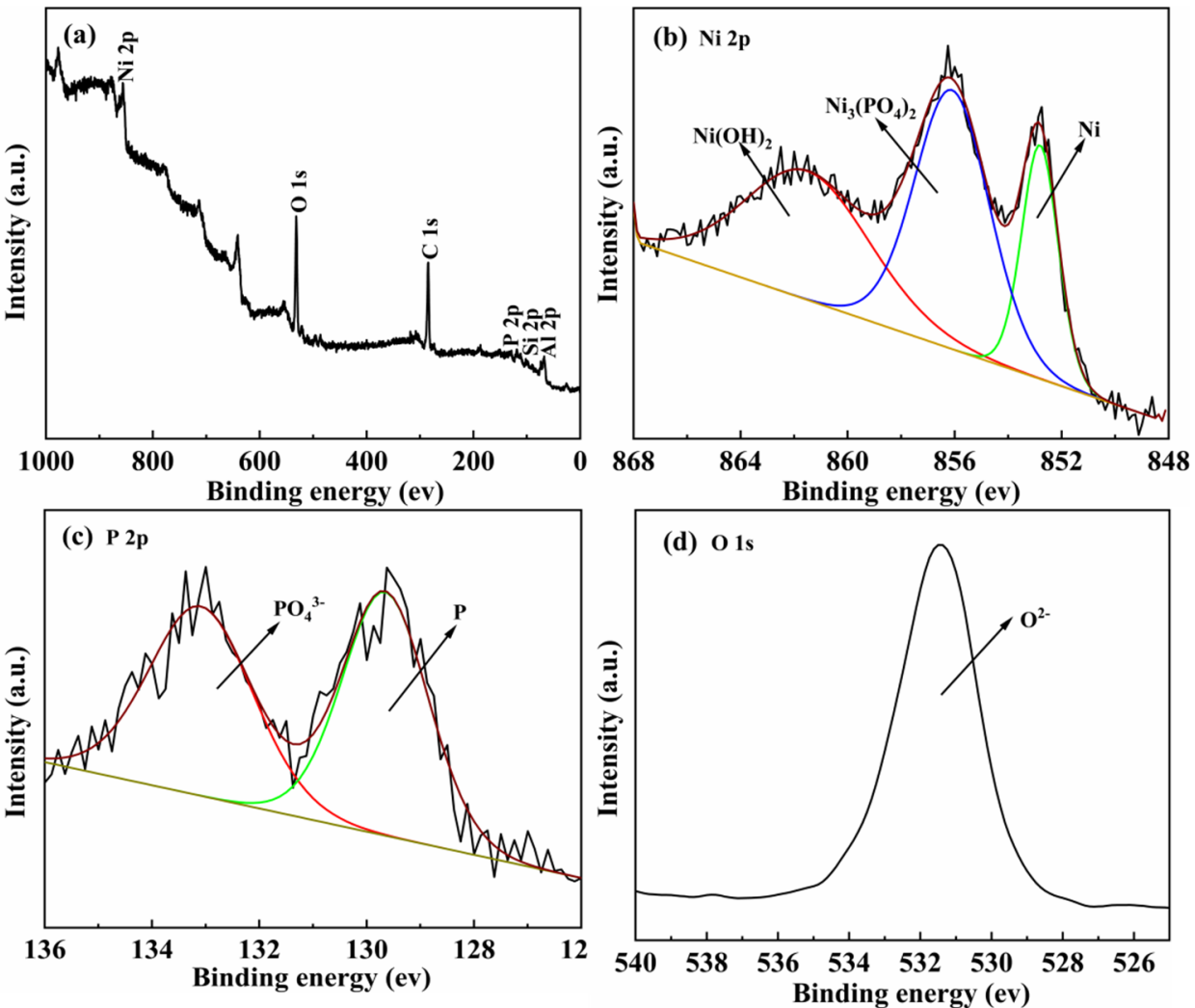

Figure 6. XPS spectra of Ni-P/mullite coated powder: (a) full spectra, (b) Ni 2p narrow spectra, (c) P $2 p$ narrow spectra and $(\mathbf{d}) \mathrm{O}$ 1s narrow spectra.
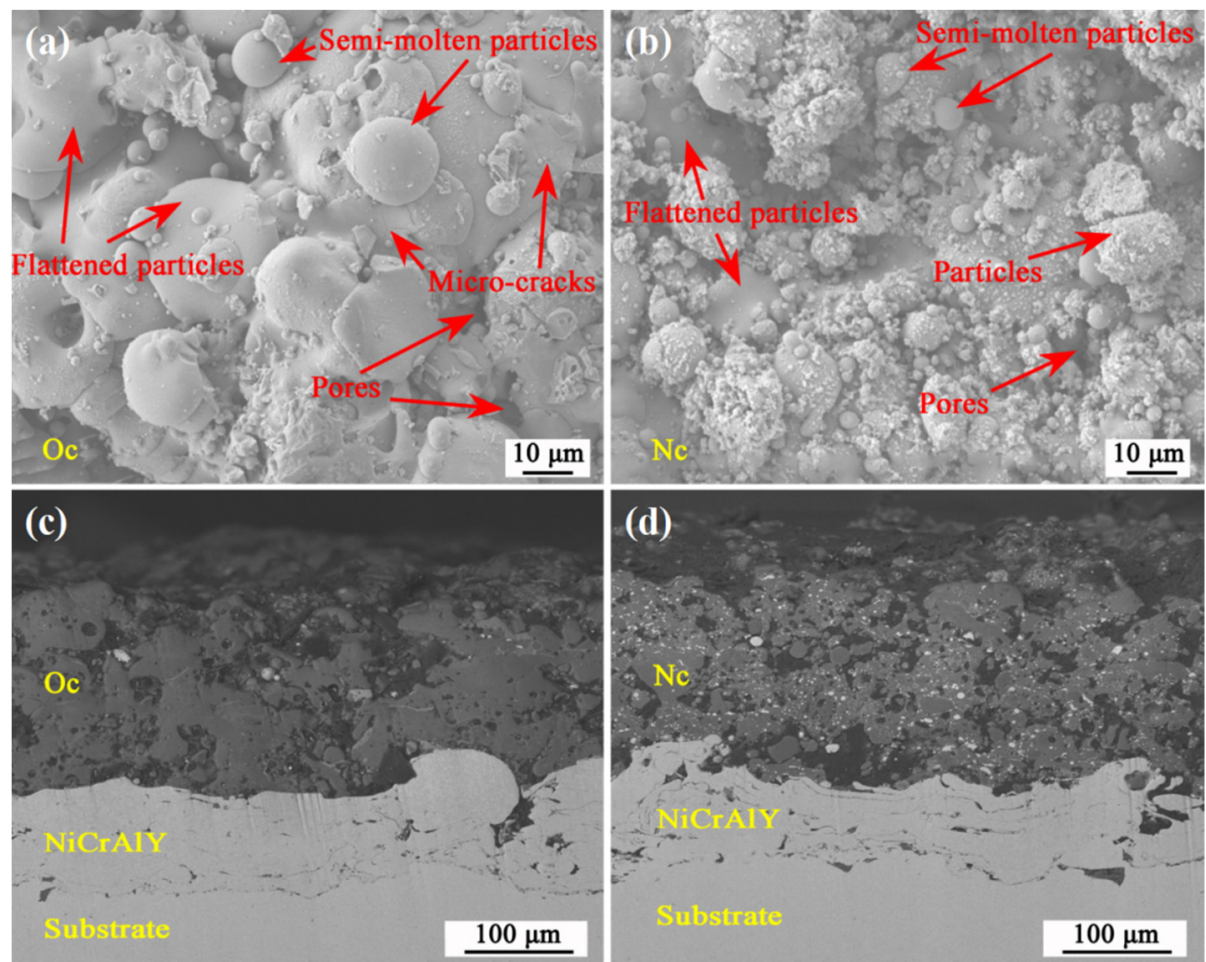

Figure 7. SEM images of the top surfaces of the as-sprayed coatings: $(\mathbf{a}) \mathrm{O}_{\mathrm{C}},(\mathbf{b}) \mathrm{N}_{\mathrm{C}}$, and (c,d) their polished cross sections (mode: BSE), respectively. 
The properties of composites depend largely on the homogeneity of the mixed phases. Figure 8 shows the surfaces of the as-sprayed mullite coatings and corresponding energy spectrum analysis. $\mathrm{Al}, \mathrm{O}$, and $\mathrm{Si}$ are uniformly distributed on the surfaces of the mullite coatings; there is no concentration of elements on the surface. Compared to $\mathrm{O}_{\mathrm{C}}$ (Figure 8a), the energy spectrum analysis of $\mathrm{N}_{C}$ (Figure $8 \mathrm{~b}$ ) shows that Ni elements are uniformly distributed in the top coating.
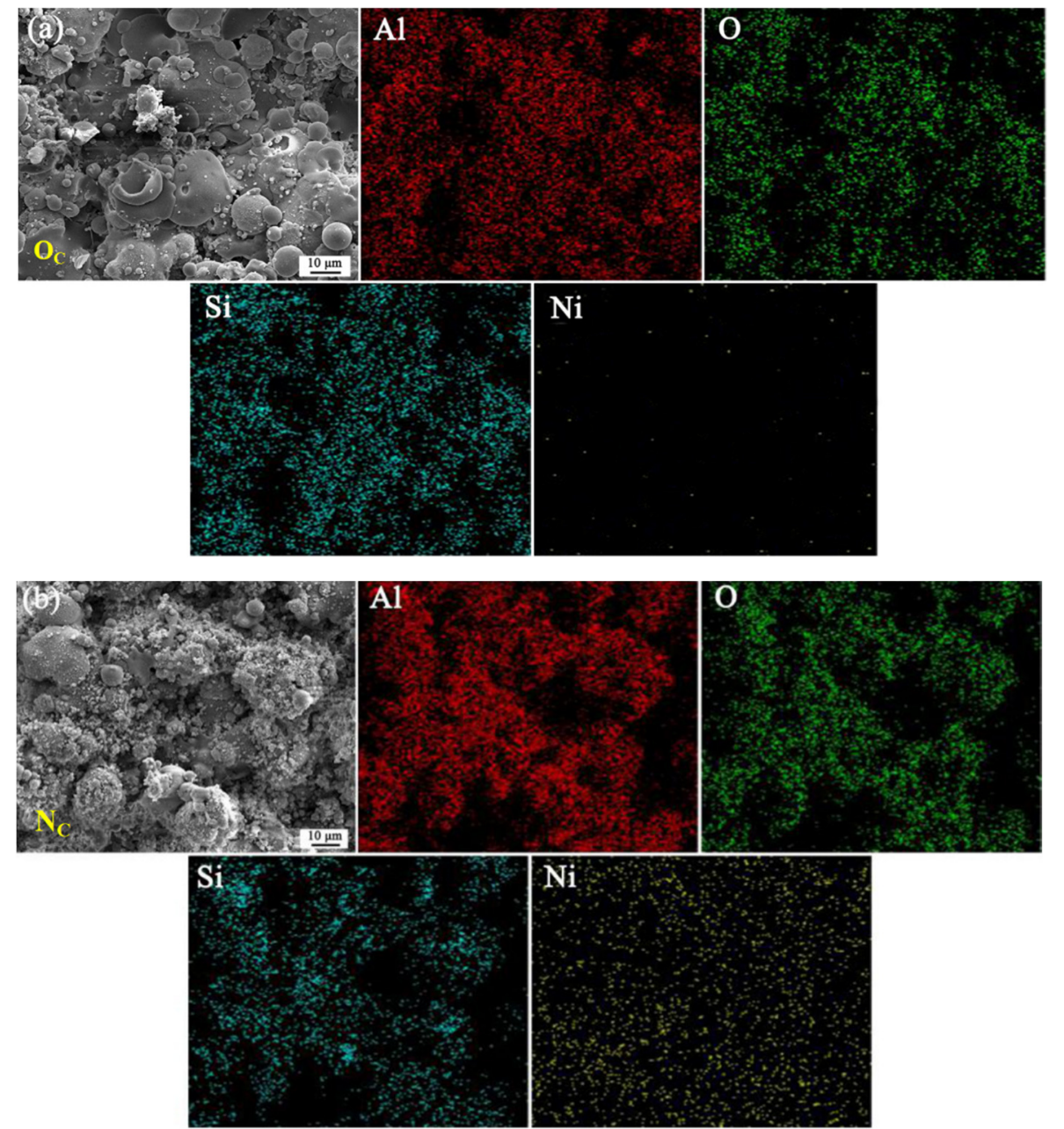

Figure 8. SEM images of the surfaces of the mullite coatings and corresponding energy. Spectrum analysis: (a) $\mathrm{O}_{\mathrm{C}}$, (b) $\mathrm{N}_{\mathrm{C}}$.

Figure 9 shows the XRD patterns of the as-sprayed mullite coatings. $\mathrm{O}_{\mathrm{C}}$ is mainly composed of mullite, whereas $\gamma-\mathrm{Al}_{2} \mathrm{O}_{3}$ is present as a minor phase. In addition, there is a broad band of an amorphous phase at $2 \theta$ between $20^{\circ}$ and $40^{\circ}$. The existence of the amorphous phase is attributed to the large temperature gradient between the molten particles and substrate. The molten particles quickly hit the substrate and rapidly cool to form the amorphous phase. In addition, the metastable $\gamma-\mathrm{Al}_{2} \mathrm{O}_{3}$ phase in $\mathrm{O}_{\mathrm{C}}$ does not change to the stable $\alpha-\mathrm{Al}_{2} \mathrm{O}_{3}$ owing to the high cooling rate [28]. The XRD pattern shows that $\mathrm{N}_{\mathrm{C}}$ (Figure $9 \mathrm{~b}$ ) is mainly composed of mullite, $\mathrm{Ni}, \mathrm{Ni}_{3} \mathrm{P}$, and $\mathrm{AlNi}_{3}$ phases. The crystal peak of mullite is attributed to the molten particles but also originates from the unfused mullite particles embedded on the substrate. The high-speed plasma flame melts the Ni-P layer on the surface of the coated mullite powders and some coated mullite powders, forming hard phases such as $\mathrm{Ni}_{3} \mathrm{P}$ and $\mathrm{AlNi}_{3}$, which is beneficial to the improvement in hardness. 


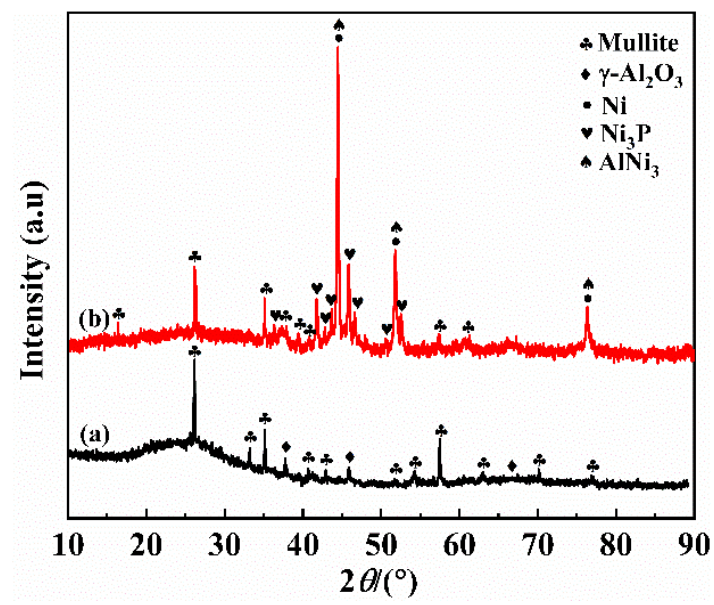

Figure 9. XRD patterns of the as-sprayed coatings: (a) $\mathrm{O}_{\mathrm{C}}$, (b) $\mathrm{N}_{C}$.

\subsection{Hardness and Thermal Conductivity of the Coatings}

Hardness is one of the main indices of wear resistance of the coating. Because of some inherent defects of plasma spraying, the hardness and porosity of the spraying coating are different from those of their corresponding bulk materials. Figure 10 shows the hardnesses and porosities of the substrate, bonding coating, and coatings. The hardness gradually increases from the substrate to $\mathrm{N}_{\mathrm{C}}$. The porosities (measured by version Image J) of Oc and Nc are $11.15 \% \pm 0.32 \%$ and $7.40 \% \pm 0.51 \%$, respectively, which implies that the introduction of the Ni-P layer leads to a minor reduction in porosity of the mullite coating. The bonding coating also has a small amount of pores; the substrate is a bulk material without pores. The hardness of the coating is related to the number of lipostomous in the coating. Compared to the Vickers hardness of $\mathrm{O}_{\mathrm{C}}(417.5 \pm 46.1 \mathrm{HV})$, the hardness of $\mathrm{N}_{\mathrm{C}}(500.1 \pm 33.6 \mathrm{HV})$ is significantly increased. This can be explained as the introduction of the Ni-P layer not only reduces the internal pores of $\mathrm{N}_{C}$ and improves the compactness, but also leads to the formation of hard phases such as $\mathrm{Ni}_{3} \mathrm{P}$ and $\mathrm{AlNi}_{3}$ in $\mathrm{N}_{\mathrm{C}}$. The unmelted mullite powders in $\mathrm{N}_{\mathrm{C}}$ also increase the hardness of the coating. A proper coating porosity is helpful to enhance the thermal insulation properties in high-temperature applications. However, a high porosity is harmful to the protection of the metallic substrate and service life of the coating at a high temperature. The pores are similar to channels; oxygen permeates through the open pores and reacts with the bonding layer to form oxides, which reduces the service life of the coating $[29,30]$.

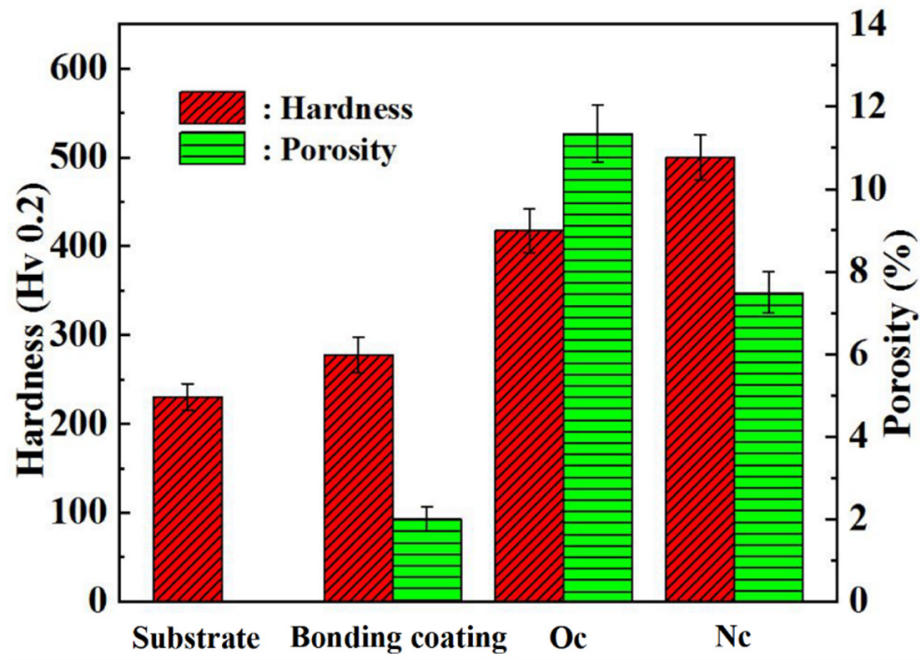

Figure 10. Hardnesses and porosities of the substrate, bonding coating and as-sprayed coatings. 
Thermal insulation is crucial for the TBC. A functional TBC can effectively hinder the heat transfer between the environment and substrate. Table 4 shows the densities, specific heat capacities, thermal diffusivities, and thermal conductivities of the as-sprayed coatings at $25^{\circ} \mathrm{C}$. The density of $\mathrm{N}_{\mathrm{C}}$ is slightly larger than that of $\mathrm{O}_{\mathrm{C}}$, owing to the Ni-P layer and to the fewer pores in $\mathrm{N}_{C}$. According to the TPS measurement, the thermal conductivities of Oc and Nc are 3.356 and $3.540(\mathrm{~W} / \mathrm{m} \cdot \mathrm{K})$, respectively. The measured thermal conductivities are different from the reported values of 1 to $2.8(\mathrm{~W} / \mathrm{m} \cdot \mathrm{K})[11,30]$, which may be related to the measurement method and coating thickness [31]. The thermal insulation performance of the coating prepared by APS is directly proportional to the coating thickness. In other studies, the thicknesses of TBCs were 500 to $1000 \mu \mathrm{m}$, while that in this study is approximately $200 \mu \mathrm{m}$, so that the thermal conductivity is increased. When heat is transferred in the coating, the pores of the coating can cause turbulence to the propagation path of the phonons in the heat transfer medium [32]. In the plasma sprayed coatings, the pores are basically flat and parallel to the substrate, which increases the resistance against the heat flow in the vertical direction across the whole coating. Thus, a proper porosity is helpful to the thermal insulation of the coating. Although the low porosity of $\mathrm{N}_{\mathrm{C}}$ is harmful to the thermal barrier properties of the coating, the crystal structure of $\mathrm{N}_{C}$ is complex with numerous heterogeneous phases, which enhance the scattering of electrons and phonons in the heat transfer medium and largely affect the heat transfer ability of the coating. Therefore, compared to $\mathrm{O}_{\mathrm{C}}$, the introduction of the Ni-P layer in $\mathrm{N}_{\mathrm{C}}$ does not significantly increase its thermal conductivity.

Table 4. Densities, specific heat capacities, thermal diffusivities, and thermal conductivities of the as-sprayed coatings.

\begin{tabular}{ccccc}
\hline Sample & Density $\left(\mathbf{g} / \mathbf{c m}^{\mathbf{3}}\right)$ & $\begin{array}{c}\text { Specific Heat } \\
\text { Capacity } \\
\mathbf{( k J / k g} \cdot \mathbf{K})\end{array}$ & $\begin{array}{c}\text { Thermal } \\
\text { Diffusivity } \\
\left(\mathbf{m m}^{\mathbf{2}} / \mathbf{S}\right)\end{array}$ & $\begin{array}{c}\text { Thermal } \\
\text { Conductivity } \\
\mathbf{( W / m} \cdot \mathbf{K})\end{array}$ \\
\hline $\mathrm{O}_{\mathrm{C}}$ & 2.744 & 1.353 & 0.904 & 3.356 \\
$\mathrm{~N}_{\mathrm{C}}$ & 3.015 & 0.976 & 1.203 & 3.540 \\
$\mathrm{Oc} / \mathrm{Nc}(\%)$ & 91.01 & 138.63 & 75.15 & 94.80 \\
\hline
\end{tabular}

\subsection{Thermal Cycling Resistances of the Coatings}

Figure 11 shows digital photographs of the thermal shock cycling of the coatings. Before the cycles of thermal shock, $\mathrm{N}_{\mathrm{C}}$ (Figure 11b1-b3) is grayish black, owing to the coated mullite powders. After 8 cycles of thermal shock, the color of $\mathrm{O}_{\mathrm{C}}$ (Figure 11a1-a3) changes to yellowish brown and the edge of the coating is slightly detached from the substrate. After 12 cycles of thermal shock, the spalling area the edge of $\mathrm{O}_{\mathrm{C}}$ expands slightly and a considerable spalling occurs at the center of the coating. At this time, the $\mathrm{O}_{\mathrm{C}}$ is considered to fail. After 15 thermal shocks, $\mathrm{N}_{\mathrm{C}}$ becomes gray and slightly peels off locally. When $\mathrm{N}_{C}$ is subjected to 23 cycles of thermal shock, the spalling area of the coating is considerably increased, but no spalling occurs at the edge of $\mathrm{N}_{\mathrm{C}}$. At this time, $\mathrm{N}_{\mathrm{C}}$ fails. During the thermal shock, the main reasons for coating failure are the mismatch in CTE and formation of thermally grown oxide (TGO) $[33,34]$. When $\mathrm{O}_{\mathrm{C}}$ is subjected to thermal shock, the $C T E s$ of $\mathrm{O}_{C}$ and bonding layer are not matched (mullite, $5.3 \times 10^{-6} / \mathrm{K}_{\text {; }}$ NiCrAlY, $\left.15.4 \times 10^{-6} / \mathrm{K}\right)$, which accumulates residual stress at the interface between the coating and bonding layer. With the increase in the number of thermal shocks, the residual stress increases gradually and ultimately leads to the failure of the coating [35]. In $\mathrm{N}_{C}$, the introduction of the Ni-P layer can effectively improve the CTE of the coating and increase the wettability and adhesion between the coating and the bond layer, which can effectively reduce the spalling of the coating. Moreover, the pores are important channels for the generation of TGO. A proper thickness of TGO is useful to prevent further oxidation of the coating and improve the system durability. However, a large residual stress is formed when the thickness of TGO is too large, which eventually leads to the failure of the coating [36]. 
Compared to $\mathrm{O}_{C}$, the reduction of pores in $\mathrm{N}_{C}$ effectively prevents the formation of TGO and improves the service life of the coating at high temperatures.

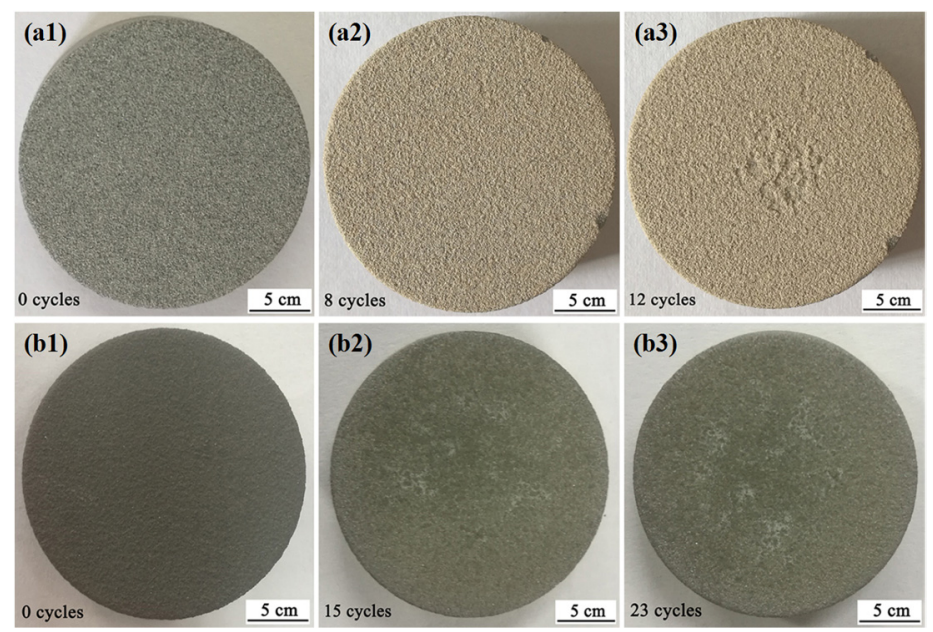

Figure 11. Digital photographs during the thermal shock cycling of the as-sprayed coatings: (a1) $\mathrm{O}_{\mathrm{C}}$ 0 cycles, (a2) $\mathrm{O}_{C} 8$ cycles, (a3) $\mathrm{O}_{\mathrm{C}} 12$ cycles, (b1) $\mathrm{N}_{C} 0$ cycles, (b2) $\mathrm{N}_{C} 15$ cycles, (b3) $\mathrm{N}_{C} 23$ cycles.

\section{Conclusions}

The mullite powders were coated with the Ni-P layer by electroless plating. The coated mullite powders and original mullite powders were then plasma-sprayed onto 304 stainless-steel substrates to form mullite coatings. The growth mechanism of the Ni-P layer, microstructures and phase compositions of the coated powders, and properties of the as-sprayed coatings were investigated. The conclusions of this study can be summarized as follows:

1. The Ni-P layer could be coated on the surface of mullite powders by electroless plating. The layer of coated powder was uniform and dense, without leakage or aggregation.

2. In the electroless plating, $\mathrm{Ni}^{2+}$ was absorbed on the surface of the pretreated mullite and reduced to nucleate growth near the $\mathrm{Pd}$ atom, forming an island-like structure. With the reaction, Ni particles grew and aggregated in three dimensions, forming a $\mathrm{Ni}-\mathrm{P}$ layer film on the surface of the mullite. The Ni particles formed on the surface of the film served as activation centers for reaction continuation.

3. Compared to the original mullite coating, the composite coating with the Ni-P layer exhibited a better wettability, lower porosity, higher hardness, and larger binding force under the condition that the thermal conductivity is not significantly different from that of the original mullite coating. This study provides a feasible approach for the applications of mullite as a wear-resistance material of harsh environments, environmental barrier coatings (EBCs) of the ceramic matrix composite material and $\mathrm{TBC}$ of lower-temperature environments.

Author Contributions: Conceptualization, K.C.; Formal analysis, K.C.; Investigation, P.Z. and X.N.; Project administration, P.Z.; Writing-original draft, K.C.; Writing-review and editing, P.S., X.N. and C.H. All authors have read and agreed to the published version of the manuscript.

Funding: This study was supported by Research Projects of Higher-Education Institutions in Gansu Province (2017D-02).

Institutional Review Board Statement: Not applicable.

Informed Consent Statement: Not applicable.

Data Availability Statement: Data is contained within the article.

Conflicts of Interest: There are no conflict of interest to declare. 


\section{References}

1. Padture, N.P.; Gell, M.; Jordan, E.H. Thermal barrier coatings for gas-turbine engine applications. Science 2002, 296, 280-284. [CrossRef]

2. Cao, X.Q.; Vassen, R.; Stoever, D. Ceramic materials for thermal barrier coatings. J. Eur. Ceram. Soc. 2004, 24, 1-10. [CrossRef]

3. Vaßen, R.; Jarligo, M.O.; Steinke, T.; Mack, D.E.; Stöver, D. Overview on advanced thermal barrier coatings. Surf. Coat. Technol. 2010, 205, 938-942. [CrossRef]

4. Vaßen, R.; Kagawa, Y.; Subramanian, R.; Zombo, P.; Zhu, D. Testing and evaluation of thermal-barrier coatings. MRS Bull. 2012, 37, 911-916. [CrossRef]

5. Ghasemi, R.; Shoja-Razavi, R.; Mozafarinia, R.; Jamali, H. The influence of laser treatment on thermal shock resistance of plasma-sprayed nanostructured yttria stabilized zirconia thermal barrier coatings. Ceram. Int. 2014, 40, 347-355. [CrossRef]

6. Narimani, N.; Saremi, M. A study on the oxidation resistance of electrodeposited and nanostructured YSZ thermal barrier ceramic coatings. Ceram. Int. 2015, 41, 13810-13816. [CrossRef]

7. Jam, A.; Derakhshandeh, S.M.R.; Rajaei, H.; Pakseresht, A.H. Evaluation of microstructure and electrochemical behavior of dual-layer NiCrAlY/mullite plasma sprayed coating on high silicon cast iron alloy. Ceram. Int. 2017, 43, 14146-14155. [CrossRef]

8. Hu, X.X.; Xu, F.F.; Li, K.W.; Jin, G.; Xu, Y.; Zhao, X.Q. Water vapor corrosion behavior and failure mechanism of plasma sprayed mullite $/ \mathrm{Lu}_{2} \mathrm{Si}_{2} \mathrm{O}_{7}-\mathrm{Lu}_{2} \mathrm{SiO}_{5}$ coatings. Ceram. Int. 2018, 44, 14177-14185. [CrossRef]

9. Saravanan, S.; Kumar, C.R.; Pugazhendhi, A.; Brindhadevic, K. Role of thermal barrier coating and porous medium combustor for a diesel engine: An experimental study. Fuel 2020, 280, 118597. [CrossRef]

10. di Girolamo, G.; Blasi, C.; Pilloni, L.; Schioppa, M. Microstructural and thermal properties of plasma sprayed mullite coatings. Ceram. Int. 2010, 36, 1389-1395. [CrossRef]

11. Li, S.J.; Zhao, X.Q.; Hou, G.L.; Deng, W.; An, Y.L.; Zhou, H.D.; Chen, J.M. Thermomechanical properties and thermal cycle resistance of plasma-sprayed mullite coating and mullite/zirconia composite coatings. Ceram. Int. 2016, 42, 17447-17455. [CrossRef]

12. Rangaraj, S.; Kokini, K. Interface thermal fracture in functionally graded zirconia-mullite-bond coat alloy thermal barrier coatings. Acta Mater. 2003, 51, 251-267. [CrossRef]

13. Bolelli, G.; Cannillo, V.; Lugli, C.; Lusvarghi, L.; Manfredini, T. Plasma-sprayed graded ceramic coatings on refractory materials for improved chemical resistance. J. Eur. Ceram. Soc. 2006, 26, 2561-2579. [CrossRef]

14. Naebe, M.; Shirvanimoghaddam, K. Functionally graded materials: A review of fabrication and properties. Appl. Mater. Today 2016, 5, 223-245. [CrossRef]

15. Wang, C.; Cui, X.F.; Jin, G.; Gao, Z.H.; Jin, J.N.; Cai, Z.B.; Fang, Y.C. Ceramic Fibers Reinforced Functionally Graded Thermal Barrier Coatings. Adv. Eng. Mater. 2017, 19, 1700149. [CrossRef]

16. Zhang, X.F.; Song, J.B.; Deng, Z.Q.; Wang, C.; Niu, S.P.; Liu, G.; Deng, C.M.; Deng, C.G.; Liu, M.; Zhou, K.S.; et al. Interface evolution of $\mathrm{Si} / \mathrm{Mullite} / \mathrm{Yb}_{2} \mathrm{SiO}_{5}$ PS-PVD environmental barrier coatings under high temperature. J. Eur. Ceram. Soc. 2020, 40, 1478-1487. [CrossRef]

17. Vakilifard, H.; Ghasemi, R.; Rahimipour, M. Hot corrosion behaviour of plasma-sprayed functionally graded thermal barrier coatings in the presence of $\mathrm{Na}_{2} \mathrm{SO}_{4}+\mathrm{V}_{2} \mathrm{O}_{5}$ molten salt. Surf. Coat. Technol. 2017, 326, 238-246. [CrossRef]

18. Luo, H.; Leitch, M.; Zeng, H.B.; Luo, J.L. Characterization of microstructure and properties of electroless duplex Ni-W-P/Ni-P nano- $\mathrm{ZrO}_{2}$ composite coating. Mater. Today. Phys. 2018, 4, 36-42. [CrossRef]

19. Fan, L.; Wang, Q.; Yang, P.; Chen, H.H.; Hong, H.P.; Zhang, W.T.; Ren, J. Preparation of nickel coating on ZTA particles by electroless plating. Ceram. Int. 2018, 44, 11013-11021. [CrossRef]

20. Liu, W.N.; Qiao, X.J.; Liu, S.; Shi, S.M.; Liang, K.; Tang, L. A new process for pre-treatment of electroless copper plating on the surface of mica powders with ultrasonic and nano-nickel. J. Alloy. Compd. 2019, 791, 613-620. [CrossRef]

21. Kong, D.H.; Zuo, X.Q.; Wang, Y.W.; Zhou, Y. Microstructure and thermal decomposition property of $\mathrm{Ni}-\mathrm{P} / \mathrm{Cr} 2 \mathrm{~N}$ composite powder by electroless plating. Adv. Powder Technol. 2018, 29, 1433-1438. [CrossRef]

22. Dai, H.; Li, H.; Wang, F. Electroless Ni-P coating preparation of conductive mica powder by a modified activation process. Appl. Surf. Sci. 2006, 253, 2474-2480. [CrossRef]

23. Yuan, X.T.; Sun, D.B.; Yu, H.Y.; Meng, H.M.; Fan, Z.S.; Wang, X.D. Preparation of amorphous-nanocrystalline composite structured Ni-P electrodeposits. Surf. Coat. Technol. 2007, 202, 294-300. [CrossRef]

24. Chen, J.; Zhao, G.L.; Matsuda, K.; Zou, Y. Microstructure evolution and corrosion resistance of Ni-Cu-P amorphous coating during crystallization process. Appl. Surf. Sci. 2019, 484, 835-844. [CrossRef]

25. Ghavidel, N.; Allahkaram, S.R.; Naderi, R.; Barzegar, M.; Bakhshandeh, H. Corrosion and wear behavior of an electroless $\mathrm{Ni}-\mathrm{P} /$ nano-SiC coating on AZ31 Mg alloy obtained through environmentally-friendly conversion coating. Surf. Coat. Technol. 2020, 382, 125156. [CrossRef]

26. van den Brand, J.; Sloof, W.G.; Terryn, H.; de Wit, J.H.W. Correlation between hydroxyl fraction and O/Al atomic ratio as determined from XPS spectra of aluminium oxide layers. Surf. Interface. Anal. 2004, 36, 81-88. [CrossRef]

27. An, Y.L.; Chen, J.M.; Zhou, H.D.; Liu, G. Microstructure and thermal cycle resistance of plasma sprayed mullite coatings made from secondary mullitized natural andalusite powder. Surf. Coat. Technol. 2010, 205, 1897-1903. [CrossRef] 
28. Li, S.J.; Xi, X.; Hou, G.L.; An, Y.L.; Zhao, X.Q.; Zhou, H.D.; Chen, J.M. Preparation of plasma sprayed mullite coating on stainless steel substrate and investigation of its environmental dependence of friction and wear behavior. Tribol. Int. 2015, 91, 32-39. [CrossRef]

29. Rad, M.R.; Farrahi, G.H.; Azadi, M.; Ghodrati, M. Stress analysis of thermal barrier coating system subjected to out-of-phase thermo-mechanical loadings considering roughness and porosity effect. Surf. Coat. Technol. 2015, 262, 77-86.

30. See, A.; Hassan, J.; Hashim, M.; Wahab, Z.A. Thermal diffusivity of kaolinite-mullite ceramic matrix composite with silicon nitride nanoparticle filler. Thermochim. Acta. 2014, 593, 76-81. [CrossRef]

31. Izadinia, M.; Soltani, R.; Sohi, M.H. Effect of segmented cracks on TGO growth and life of thick thermal barrier coating under isothermal oxidation conditions. Ceram. Int. 2020, 46, 7475-7481. [CrossRef]

32. Foroushani, M.H.; Shamanian, M.; Salehi, M.; Davar, F. Porosity analysis and oxidation behavior of plasma sprayed YSZ and $\mathrm{YSZ} / \mathrm{LaPO}_{4}$ abradable thermal barrier coatings. Ceram. Int. 2016, 42, 15868-15875. [CrossRef]

33. Liu, P.F.; Jiang, P.; Sun, Y.L.; Xu, R.; Wang, T.J.; Zhang, W.X. Numerical Analysis of stress evolution in thermal barrier coating system during two-stage growth of heterogeneous oxide. Ceram. Int. 2021, 47, 14311-14319. [CrossRef]

34. Shen, Z.Y.; Liu, G.X.; Mu, R.D.; He, L.M.; Xu, Z.H.; Dai, J.W. Effects of Er stabilization on thermal property and failure behavior of $\mathrm{Gd}_{2} \mathrm{Zr}_{2} \mathrm{O}_{7}$ thermal barrier coatings. Corros. Sci. 2021, 185, 109418. [CrossRef]

35. Hussain, N.; Qayyum, F.; Pasha, R.A.; Shah, M. Development of multi-physics numerical simulation model to investigate thermo-mechanical fatigue crack propagation in an autofrettaged gun barrel. Def. Technol. 2021, 17, 1579-1591. [CrossRef]

36. Mukhtar, F.; Qayyum, F.; Elahi, H.; Shah, M. Studying the effect of thermal fatigue on multiple cracks propagating in an SS316L thin flange on a shaft specimen using a multi-physics numerical simulation model. J. Mech. Eng. 2019, 65, 565-573. [CrossRef] 